\title{
DOCUMENTARIO
}

\section{Resultados e. Perspectivas do Sistema de Cooperação Bilateral do Ponto IV (*)}

\section{J. Guilherme de Aragõ̃o}

Ninguém mais autorizado do que o $S t$. João Guilherme de Aragão para falar sôbre o chamado Ponto IV. Não apenas pela sua condição de Representante do Govêrno do Brasil junto aos órgãos executivos do programa previsto no acôrdo brasileiro-americano. Mas, sobretudo suas qualidades de jurista e de profundo conhecedor dos problemas da administração o credenciam para a análise de assunto tão complexo.

Numa sociedade internacional dividida em áreas ou blocos que procuram, com alianças, tratados ou esquemas politicos, se fortificar ou se constituir em exemplo de progresso econômico e social, o panorama das relações brasileiro-americanas não poderia deixar de refletir êsse estado de espirito que marca, sem dúvida, o caráter da vida internacional dos nossos dias.

Com quase nove anos de execução, e com um acervo de realizaçôes animadoras, o programa do Ponto IV comporta ainda uma série de possibilidades concretas, no campo das rela ções entre os dois paises, contratantes, onde o fator fratetnidade, cada vez maior, não será, de certo, o de menor valor.

Uma visão segura do que, a êsse respeito, já foi feito, sem alarde ou publicidade, e do que ainda resta por fazer, é o que - leitor encontrará na conferência que temos a honra de trans. crever.

Desde o momento em que atingiram a maioridade politica, os países do continente americano despertaram para o sentimento de fraternidade e cooperação. A êsse respeito, a doutrina de MONROE é, por assim dizer, o primeiro instrumento político daquela expressão sentimental.

(*) Conferência pronunciada, a 6 de março de 1959, no auditório da Embaixada americana, sob os auspícios do Instituto Brasil-Estados Unidos. 
Após sua manifestação idealista, entretanto, revoluções sucessivas e às vêzes concomitantes transformaram o mundo: cairam as fronteiras geográficas pela comunicação crescente entre os povos; a técnica transformou os tipos de convivência humana; as sociedades em contatos diuturnos pelos meios hodiernos de comunicações se homogenizaram em sistemas uniformes ou paralelos de normas, de princípios e até mesmo de hábitos; enfim, passaram os países, do isolamento nacional à corrente internacional solidária, e daí juristas como Kelsen e Gurvitch; sociólogos como Sorokin e Berdiaeff, Emery R $\overline{\text { VES}}$, sonham nova passagem, agora para o plano de solidariedade universal. Nessa evolução tridimensional - da convivência nacional à internacional, desta à convivência universal - as relações entre os povos vieram pouco a pouco adquirindo matiz, fôrça e riqueza, e, conseqüentemente, forjando um tipo próprio de solidariedade. Assim, no estágio de afirmação taacional, de que é lídima expressão o instituto da soberania, a solidariedade é de tipo jurídico. A irrupção, desde os fins do século XVIII até a metade do século XIX, das nações independentes da América se realiza em nome do direito. A união entre os povos se faz românticamente através do liame juridico. No estágio ulterior de afirmação da convivência internacional e de ordenação à convivência universal, a união se lastreia e fortalece em vinculos muito mais sensiveis e pragmático's de solidariedade social e econômica. A doutrina de MONROE pertence ao tempo da solidariedade juridica entre povos americanos. Hoje, vários instrumentos formalmente jurídicos; materialmente, porém, de ordem social e econômica, cimentam as relaçóes dos povos do continente americano e, particularmente, as relações com os Estados Unidos. Refiro-me aos sistemas de cooperação internacional e, especificamente, de cooperação bilateral de que o Ponto IV, objeto desta conferência, é a expressão mais atual e atuante.

Podemos, assim, finalizar êste exórdio configurando o Ponto IV como sistema de cooperação bilateral entre o Brasil e os Estados Unidos, tendente ao desenvolvimento social e econômico de nosso país. Nenhum outro acôrdo bilateral tão bem sincroniza com a programação administrativa do govêrno do Presidente Juscelino KuBITSCHeK cujo dinamismo vem sendo dirigido exatamente àquele fim.

Para ressaltar a afinidade entre os objetivos específicos do Ponto IV e os dos programas governamentais consubstanciados nas "metas", basta relembrar tópicos do contexto dos dois documentos, que dão fundamento ao sistema bilateral do Ponto IV. O primeiro dêles - o Acôrdo Geral de Coope. ração Técnica - firmado a 19 de dezembro de 1950 estabelece as bases de uma cooperação reciproca de intercâmbio de métodos, conhecimentos técnicos e atividades correlatas, destinadas a contribuir para o desenvolvimento equilibrado e coordenado do potencial econômico e o aumento da produção do Brasil». E acrescenta: «A execução de determinados programas técnicos e a elaboração de projetos especificos serão feitas mediante acôrdos especiais ou entendimentos que venham a ser ultimados entre representantes devidamente autorizados pelo Govêrno do Brasil e pela Administração de Assistência Téenica dos Estados Unidos da América, ou outros representantes, devidamente autorizados, dos Estados Unidos da América ou, ainda, entre outras. 
entidades ou pessoas designadas pelos respectivos Governos». O segundo documento, complementar do primeiro, refere-se ao acôrdo entre o Brasil e os Estados Uníidos sôbre a prestação de serviços técnicos especiais. Diz o texto que: "O Govêrno dos Estados Unidos da América porá à disposição do Govêrno dos Estados Unidos do Brasil, sempre que êste os solicitar e aquêle concordar, os serviços de técnicos e especialistas em qualquer setor de atividade que se relacione com o desenvolvimento econômico dos Estados Unidos do Brasil e que se enquadre nos objetivos do programa de cooperação técnica dos Estados Unidos da América". Ainda: "Serviços técnicos serão postos à disposição do Govêrno dos Estados Unidos do Brasil, nos têrmos dêste Acôrdo, quando, solicitados e concedidos, não estejam previstos nos Acôrdos de Programas referentes a setores de atividades específicas que já tenham sido ou venham a ser celebrados entre as Partes Contratantes".

Assim configurádo através dêsses dois instrumentos, o sistema de cooperação bilateral, ao mesmo tempo que impunha ordem às tentativas anteriores de igual natureza, viria projetar um dos mais fecundos sistemas de entendimento brasileiro-americano polarizado para o objetivo comum de nosso desenvolvimento nacional. Erigiu-se, por tal meio, um regime de administração bilateral específica, que já produziu resultados construtivos apreciáveis e, no momento, abre perspectivas mais amplas de cooperação, que pode assumir maior significação e importância em face dos novos enunciados da politica continental: Referir ou, melhor, resumir aquêles resultados, bem como delinear as novas perspectivas - eis a substância desta conferência.

Inicialmente, a extensão dos indices até agora alcançados através do sistema de cooperação bilateral do Ponto IV pode ser mais nitidamente delimitada, se fixarmos o âmbito em que êle opera e atua. Em primeiro lugar, os dois documentos basilares conduzem à propositura e conseqüente implantação de numerosos programas administrativos. Como a administração pública brasileira está estruturada, aliás, de acôrdo com a experiência e a doutrina ameriçana (Willoughby, Walters'); em função de duas ordens de atividades - atividades-meio ou de administração geral, e atividades-fins ou de administração especifica, é possivel discernir, no conjunto dos programas, os que se dirigem pròpriamente ao primeiro tipo de atividade, ou seja, os programas de administração geral, e os que se situam na ordem de atividades-fins, ou seja, de administração específica. No primeiro caso, figuram os programas tendentes ao fortalecimento em geral da administração pública no Brasil, através da assistência técnica em matéria de administração de pessoal, de administração orçamentária e financeira, de organização e métodos. No segundo, avultam numerosos programas dirigidos a setores específicos de agricultura, saúde, recursos minerais, ensino, transportes, desenvolvimento de comunidades, turismo, comunicação áudio visual, energia nuclear, instalação de equipamentos de radar etc.

Eis o vasto campo de incidência do Ponto IV. Agora vamos às realizações e aos resultados, para dai infletir sôbre as atuais perspectivas do Ponto IV. $\mathrm{E}$ para fazê-lo ordenadamente, volvamos aos setores fundamentais da Administração Pública em geral, e da Administração especifica. 


\section{PROGRAMA DE ADMINISTRAÇ̃̃O PÚBLICA - ADMINISTRAÇÃO GERAL}

Dissemos que um dos efeitos imediatos do estabelecimento da ccoperação bilateral do Ponto IV consistiu em fundir iniciativas anteriores de mútua colaboração entre o Brasil e os Estados Unidos. Isto acontece em cada qual dos setores referidos. É sabido que, no domínio da administração pública, já se havia iniciado desde a instituição do D.A.S.P. um regime de intercâmbio profissional. Antes de 1950, dezenas de funcionários brasileiros tinham ido aos Estados Unidos e peritos americanos vieram ao Brasil. O Ponto IV, entretanto, é que deu consistência à cooperação bilateral neste setor. E fato significativo, sua primeira manifestação exerceu-se na assistência técnica à elaboração do Plano de Classificação de Cargos, em 1952.

Posteriormente, em 1954, dispôs-se o Ponto IV, por meio de contrato com a Universidade do Estado de Michigan, a fornecer professôres à Escola de Administração de Emprêsas, em São Paulo, expandindo-se, assim, a cooperação para o domínio da administração privada. E diga-se a verdade, a Escola de Emprêsas de São Paulo, estruturada nos moldes das Escolas de «Business Administration" dos Estados Unidos, é hoje instituição onde jovens recebem treinamento moderno de administração de grandes emprêsas. Ali con siderável número de dirigentes completaram cursos rápidos e intensivos de especialização. Mais de 25 professôres assistentes da Escola já receberam treinamento complementar nos Estados Unidos, habilitando-se no magistério especializado a ser exercido, após o regresso ao país.

Constituiu-se a Escola de São Paulo, a primeira no gênero, na América Latina, em exemplo concreto da cooperação prestada pelo Ponto IV. Também os Estados e Municipios já foram beneficiados pela assistência técnica do Ponto IV em matéria de administração pública. De 1955 a 1959, dois consultores norte-americanos vêm colaborando com a administração municipal de Belo Horizonte no aperfeiçoamento de seus métodos administrativos. Mais de 20 funcionários daquela municipalidade receberam treinamento nos Estados Unidos.

Em São Paulo, elaborou-se projeto de classificação de cargos, bem como estudo da organização da polícia estadual. Receberam ainda assistência técnica de ordem administrativa, através do Ponto IV, a Superintendência da Valorização Econồmica da Amazônia, a Universidade da Bahia, a Universidade de Minas Gerais, aquela, com a instituição de um eurso de planejamento regional; esta, com a organização de um curso de Adminiśtração Pụ blica, primeiro ná espécié a ser ministrado no sistema universitárío brasileiro.

Projeto de mais amplo porte e de estrutura mais sistemática coube por fim ao D.A.S.P. Órgão coordenador dos sistemas administrativos de orçamento, de organização e métodos e de administração de pessoal no serviço civil brasileiro, centro de irradiação de práticas administrativas para outros órgãos federais ou mesmo estaduais e municipais, nosso Departamento é detentor de extenso programa de cooperação com dois objetivos prefixados:

$\left.1 .^{\circ}\right)$ assistência direta ao D.A.S.P.;

$\left.2^{\circ}\right)$ assistência ao ensino da administração pública e administração de emprêsas. 
Inclui-se no primeiro tópico a colaboração técnica em matéria de orçamento, organização e métodos, administração do pessoal e o estabelecimento de um programa sistemático de bôlsas de estudo que permitirá a funcionários brasileiros a ida aos Estados Unidos com o objetivo de especialização em administração pública e desenvolvimentc econômico.

Técnicos do Ponto IV trabalharão neste programa em estreita colaboração com os lécniccs brasileiroj de cáda um daqueles respectivos setores e. dêsse intercâmbio, resultará o aperfeiçoamento dos métodos administrativos numa importante contribuição ao processo do desenvolvimento brasileiro.

O segundo tópico traduz projeto mais amplo de maiores repercussões no futuro. Trata-se de um programa unificado de ensino da administração pública e de emprêsas, no Brasil, do qual participarão as Universidades da Bahia, de Minas Gerais, do Rio Grande do Sul, a Fundação Getúlio Vargas e o D.A.S.P. A razão da escolha destas instituições, prende-se ao progresso que já demonstraram neste campo, bem como às vantagens de sua localiza ção geográfica que permite sejam beneficiadas várias regiões do Brasil ao mesmo tempo. Como participante dêsse programa, a Escola de Serviço Público do D.A.S.P. dispensará especial atenção ao treinamento de pessoal para o serviço público. Dezesseis técnicos norte-americanos deverão prestar sua colaboração ao prográma unificado de Administração Pública e administração de emprêsas.

\section{PROGRAMA DE ADMINISTRAÇÃO PÚBLICA - ADMINISTRAÇÃO ESPECÍFICA}

Mais ampla e variada é a cooperação no dominio da administração especifica. Pretendemos fixá-la através dos setores antes enumerados e agora individualizados para mais nitida visão particularista do trabalho conjunto realizado através do Ponto IV.

\section{AGRICULTURA}

A cooperação técnica bilateral, no campo da Agricultura, se exerce através de um órgão de administração mista, o Escritório Técnico de Agricultura criado mediante acôrdo em 1953. Tem êsse órgão por objetivo melhorar a produção agrícola no Brasil e elevar os padrões de vida do homem rural e de sua comunidade. Detentor de mais de 50 projetos, o E.T.A. promove diretamente educação e pesquisa agrícolas, de conservação de recursos naturais, de fomento da produção agrícola, incluindo o planejamento de armazéns e silos, e, finalmente, da extensão rural.

Já em 1954, o programa de cooperação agrícola entre o Brasil e os Estados Unidos permitiu que mil e quinhentas pessoas recebessem treinamento técnico no país. Estendeu-se o programa de cooperação e assistência a mais de 70 organizaçóes federais e estaduais, envolvendo no conjunto a ntuação de dois mil e quinhentos brasileiros em todo o país. Cêrca de 400 técnicos agrícolas receberam treinamento especializado nos Estados Unidos. Sòmente em 1958, cento e dezessete aperfeiçoaram seus conhecimentos em instituições daquele país. Êsses técnicos virão difundir no Brasil os conheci- 
mentos assim adquiridos. Ao mesmo tempo, estão sendo criados com a assistência do E.T.A. os clubes "4-S" que congregam a juventude rural e servem de centro de difusão dos modernos métodos agrícolas.

Entre os projetos mais importantes dêste programa fundamental, sobressai o de criação de uma Escola-Pilôto de Agricultura que servirá de centro de treinamento intensivo para professôres das Escolas Superiores de Agronomia e Veterinária de todo o país. Objetiva-se estabelecer um núcleo básico de pessoal bem treinado para impulsionar o progresso da economia agrícola brasileira. Para local de funcionamento dêste Centro-Pilôto, foi escoilhida a Universidade Rural de Viçosa que, destarte, se tornará a instituição para treinamento avançado em agricultura. Com o mesmo objetivo está sendo executado projeto de treinamento agrícola na Fazenda Ipanema, em São Paulo, onde se exercitam, na prática de extensão rural e mecânica agricola, jovens agrônomos ou agricultores que se destinam aos órgãos de extensão rural, como a Associação Brasileira de Crédito e Assistência Rural (ABCAR) e seus escritórios estaduais. Projetos experimentais e demonstrativos estão em curso desde o Amazonas ao Rio Grande do Sul, cada qual adstrito a determinado setor agrícola. Mencionam-se a respeito os programas para o desenvolvimento da borracha no Vale Amazônico, do aperfeiçoamento da qualidade e eficiência da produção cacaueira na Bahia; da produção leiteira no Recife e Cuiabá, de assistência à produção de carne e leite para Brasilia. Além dêsses, há quatro projetos de conservação de solos nos Estados de São Paulo, Rio Grande do Sul, Minas Gerais e Rio Grande do Norte.

Nesse conjunto de atividades, conta o E.T.A. com a colaboração de cêrca de 40 técnicos norte-americanos. Os recursos financeiros do programa para 1959 serão da ordem de US\$ $1.450 .000,00$ (um milhão e quatrocentos e cinqüenta mil dólares) dos quais US $\$ 300.000,00$ (trezentos mil dólares) representam a contribuição norte-americana à administração do Escritório Técnico de Agricultura.

\section{SAÛDE}

A cooperação americano-brasileira no setor de saúde procede de época anterior. Data de 1942, quando da criação do Serviço Especial de Saúde Pública, órgão incumbido de sanear o Vale Amazônico e de possibilitar a produção de borracha. Origem da assistência técnica norte-americana no Brasil, o S.E.S.P. passou, de um serviço de emergência, a ocupar posição definida na estrutura administrativa federal, cooperando com os Estados e órgãos da União na implantação de uma estrutura básica de saúde pública, em todo o pais.

A partir de 1949 , as atividades do S.E.S.P. expandiram-se progressivamente através de numerosos convênios. Além das atividades iniciais no Vale Amazônico e no Vale do Rio Doce, passou a operar na Bahia, Paraíba e Pernambuco, e, em 1950, no Vale do São Francisco. Em 1953, sob o regime de colaboração bilateral, sistemática do Ponto IV, aquela instituição projetou-se no sul do país. Por último, cobriu todo o território nacional, estendendo-se aos Estados do Rio Grande, Mato Grosso, Goiás e demais unidades da Federação. Dentro dessa expansão, o S.E.S.P. criou mais 
de 200 unidades sanitárias e centros de saúde, beneficiando milhões de pessoas. Administra, atualmente, 9 hospitais. Mais de mil médicos, enfermeiros e técnicos em saúde pública foram treinados no Brasil e nos Estados Unidos, para lhe cumprir as finalidades. Graças a sua atuação, cidades do Vale Amazônico conseguiram aumentar de 10 anos a média de vida de seus habitantes. Foram entregues sistemas de abastecimento d'água a 109 municípios brasileiros, construindo-se a Escola de Enfermagem da Universidade de São Paulo em cooperação com o Govêrno do Estado.

Vinte assessôres norte-americanos colaboram com o S.E.S.P. no continuo aperfeiçoamento de suas atividades. Os serviços do S.E.S.P. cobrem 657 localidades brasileiras e dispõem de um corpo de 3.300 funcionários. Eis brilhante exemplo da cooperação bilateral. Atualmente, a instituição para expandir ainda mais as suas atividades, afravés do mesmo sistema de cooperação bilateral do Ponto IV, está na perspectiva de uma substancial reforma de estrutura. E' que o Govêrno brasileiro, mantendo as características funcionais da instituição, pretende dar-lhe organização mais ampla. Para êsse fim, enviou mensagem e projeto de lei ao Congresso visando transformar o S. E. S. P. em fundação. Com êsse fortalecimento de estrutura, é de se esperar que ainda mais se estreite, solidifique e amplie o programa geral de saúde pública no Brasil.

De modo especial cabe mencionar o programa, iniciado na administração do Ministro Mário PINOTTI, visando à erradicação da malária. As origens recentes dêste projeto, que está sendo entusiàsticamente acolhido pela opinião pública em nosso país, estão em nossa viagem aos Estados Unidos, em 1957, a convite do Departamento de Estado. Na mesa-redonda realizada em Washington a 16 de setembro de 1957 , à indagação de um dos participantes daquele encòntro, sôbre o combate à malária no Brasil, referi que estávamos, então, estudando a criação de órgão dinâmico para cumprir o desiderato de eliminação daquela endemia. Seguiram-se entendimentos com dirigentes da Repartição de Saúde Pan-Americana em Washington e, de regresso ao Brasil, concluimos com o Ministério da Saúde, sob a orientação do Ministro Mário PinotTi, os estudos de que resultou o Decreto $\mathrm{n} .{ }^{\circ} 45.174$, de 4 de fevereiro de 1958 , base de orientação à campanha de erradicação da malária. Publicado - Decreto $n^{\circ} 43.174$, foram assinados convênios com o Ponto IV e a Organização Pan-Americana de Saúde. Através dêsse acôrdo, já destinou - Ponto IV auxílios, em inseticidas, medicamentos, veículos e equipamentos, no montante de US $\$ 4.060 .000$ dólares, sòmente para a execução do programa em 1959. Investimentos de igual ou superior importância deverão ser consig nados anualmente até o término do programa de erradicação da malária. Em suma, êsse programa se entrosa com a plano geral da repartição pan-americana de saúde, visando à eliminação da malária nos países do continente americano.

\section{MINERALOGIA E GEOLOGIA}

Também de época anterior, data o programa de cooperação bilateral no setor de recursos minerais. E' que, em 1940, geólogos norte-americanos começaram a auxiliar técnicos do Departamento Nacional da Produção Mineral a efetuar estudos sôbre as reservas minerais do Brasil. Em novembro 
de 1948, essa cooperação se concretizou em Acôrdo intergovernamental formal. Em dez anos de execução dêsse "acôrdo", têm sido tratados dois problemas gerais: o dos minérios de ferro e o dos minérios de metais não ferrosos.

Os minérios de ferro de Minas Gerais localizam-se no chamado "Quadrilátero Ferrifero». Um dos objetivos do programa consiste em identificar a geologia do centro de Minas Gerais e calcular suas reservas de minério de ferro. Muito se adiantou no andamento dêsse projeto, prevendo-se que, em 1960 , deve ser conhecido grande acervo de dados preciosos.

Os trabalhos aerofotogramétricos na área do «Quadrilátero Ferrifero» foram realizados por companhias comerciais brasileiras, sob contrato, facilitando o govêrno norte-americano a viagem de técnicos dessas companhias aos Estados Unidos para se inteirarem dos métodos modernos de compilação e reprodução de mapas.

O programa de minérios não ferrosos iniciou-se em 1956, no regime de cooperação bilateral do Ponto IV. Procede-se ao estudo das jazidas de cobre, chumbo, zinco, níquel e estanho, estimulando-lhes a pesquisa e a lavra, para que o Brasil se torne auto-suficiente nesse setor de vital importância industrial.

Como um passo à frente, o Govêrno Brasileiro, em 1957, tratou de acelerar a formação de técnicos em geologia no Brasil, donde a instituição da Campanha de Formação de Geólogos (C.A.G.E.) junto ao Ministério da Educação e Cultura. Em conseqüência, firmou-se convênio com o Ponto IV pelo qual se prevê a participação de professôres norte-americanos de Geologia nos cursos da C.A.G.E., os quais já vêm funcionando em várias universidades do pais. Além dos professôres, o convênio beneficiará os cursos com material didático e equipamento de pesquisas. Nas bases do acôrdo, os cursos da C.A.G.E. devem formar 600 brasileiros em geologia, o que significa considerável e valioso contingente de técnicos para suprir o mercado de trabalho brasileiro nesse setor. Também está previsto o treinamento em instituições especializadas dos Estados Unidos, dos estudantes que mais se distinguiram nos cursos de formação de geólogos. Êsses elęmentos, ao seu regresso, substituirão gradativamente os professôres norte-americanos. Em suma, o programa conduz a capacitar o Brasil a conhecer e explorar suas imensas reservas minerais.

\section{- ENSINO}

Desde 1946 que se criou a Comissão Brasileiro-Americana de Educação Industrial (C.B.A.I.). Esta Comissão prestou, desde então, assistência direta sob a forma de técnicos e equipamentos a vinte e três escolas industriais brasileiras.

Mas é em fevereiro de 1957 que se reorganiza a Comissão com o objetivo de permitir que a cooperação técnica se exerça através de instituição permanente. Para tal fim, criou-se o Centro Nacional de Treinamento de Professôres para o Ensino Industrial localizado na Escola Técnica de Curitiba. Nesse Centro, professôres de escolas industriais brasileiras trabalham em conjunto com os consultores norte-americanos, em diversas cadeiras, tais como carpin- 
raria, mecânica, fundição, rádio e eletricidade e trabalhos com metal. Para complementar o trabalho ora realizado, a C.B.A.I. iniciará um programa de treinamento para operários que atenda às necessidades da crescente indústria brasileira.

Outro acôrdo importante, de assistência brasileiro-americana ao ensino eiementar, foi firmado em junho de 1956. Através dêle, fundou-se a Escola de Demonstração de Ensino Elementar, localizada no Instituto de Educação de Belo Horizonte, onde mais de 700 professôres de ensino elementar serão treinados êste ano. Este projeto tem por objetivo a difusão dos métodos e técnicas modernos, bem como a demonstração de material didático de nivel mais elevado.

Dentre os professôres brasileiros escolhidos para servir à Escola de Demonstração, alguns serão enviados aos Estados Unidos para realizar estudos especializados sôbre o ensino elementar. A assistência do Ponto IV ao ensino secundário ainda está em fase de estudo e elaboração. Contudo, existe projeto que previê a criação de um Centro Pilôto de Treinamento para Professôres.

Em complemento ao ensino industrial, patrocinou o Ponto IV um programa de TWI no Brasil. O TWI - método conhecido por Treinamento dentro da Indústria - constituiu meio rápido e moderno de preparar supervisores e mestres para atender as crescentes necessidades da expansão industrial. Êsse programa já beneficiou mais de $100 \mathrm{mil}$ supervisores e operários qualificados na indústria. E' digno de registro ainda o projeto de assistência técnica prestada ao ensino têxtil através da Escola Técnica Federal de Indústria Química e Têxtil do SENAI, primeiro estabelecimento do gênero. na América Latina, vinculado, mediante acôrdos, à Organização Internacional do Trabalho e às Nações Unidas para o fim de receber alunos de outros países. Este programa compreende também o treinamento de professôres brasileiros nos Estados Unidos.

Para finalizar o escôrço do sistema de cooperação bilateral no Setor de Educação, registramos dois projetos de nivel universitário que completam a cooperação do Ponto IV em todos os niveis educacionais no Brasil. Um dêles financia professôres norte-americanos para o Instituto Tecnológico de Aero náutica em São José dos Campos, instituição de alto nível, que funciona à base de completa autonomia acadêmica nos moldes das congêneres americanas.

O outro prevê a collaboração de dois professôres norte-americanos na cadeira de Engenharia e Arquitetura Naval junto à Universidade de São Paulo. Este Curso, que é altamente especializado, enquadra-se no plano de desenvolvimento da construção naval no Brasil, sendo, portanto, de grande atualidade.

\section{TRANSPORTE}

No que respeita aos transportes, está o Ponto IV cooperando em dois setores de máxima importância: o da Navegação Aérea e o do Transporte Ferroviário.

Com relação ao primeiro, cumpre-nos consignar a grande soma de capitais investidos na instalação de aparelhos que visạm ao aperfeiçoamento do contrôle 
do tráfego aéreo. Tal se deve ao empenho do govêrno brasileiro que, ao solicitar a cooperação do Ponto IV, teve em vista equiparar a navegação aérea do Brasil à dos países mais avançados.

Através dêsse projeto, de que participa a Diretoria de Rotas Aéreas, serão instalados equipamentos altamente modernos, tais como radar VOR, Ils, luzes de aproximação de alta intensidade e rádio de micro-ondas, nos aeroportos do Rio de Janeiro. São Paulo e Pôrto Alegre. Acha-se em estudos a ampliação dêste projeto aos aeroportos de Belém e Brasilia.

O custo do equipamento previsto neste projeto atinge a quase dois milhões de dólares (US\$2,000,000,00), constituindo contribuição do Ponto IV. Inclui o programa serviços técnicos de um corpo de especialistas da Administração de Aeronáutica Civil dos Estados Unidos, bem como o treinamento, naquele pais, de técnicos brasileiros nos diferentes setores da Aeronáutica Civil.

Quanto ao setor ferroviário, o Ponto IV, em complemento ao empréstimo do Eximbank à Rêde Ferroviária Federal, está proporcionando treinamentc especializado nos Estados Unidos a grupos de engenheiros e administradores das diversas ferrovias que compõem a Rêde Ferroviária Federal.

Os técnicos enviados aos Estados Unidos, para especialização, observam, naquele pais, os métodos mais modernos de operação e manutenção das grandes emprêsas ferroviárias, prestando à sua volta, valiosos serviços às ferrovias a que pertencem.

\section{OUTROS PROJETOS}

Outros programas menores complementam os programas básicos que acabamos de enunciar: assim os de Desenvolvimento de Comunidades, Turismo, Comuniçações Áudio-visuais, Energia Nuclear, Treinamento aerofotogramétrico.

Para o programa de desenvolvimento de comunidades, escolheu-se a região do oeste paranaense. Dêle participam várias entidades interessadas como o Departamento de Fronteiras do Estado do Paraná, o Conselho Regional do Desenvolvimento, a Campanha Nacional de Educação Rural, além do E.T. A. e do S.E.S.P., órgãos, como vimos, vinculados diretamente ao Ponto IV.

O programa visa demonstrar a participação local de uma comunidade no planejamento e execução dos programas de que necessita, tais como melhoria das condições de transporte, de saúde, programas escolares e informação agrícola. O programa é complementado pelo treinamento de técnicos brasileiros nessa especialidade, nos Estados Unidos e em Pôrto Rico.

Devemos assinalar a presença entre nós de ilustre especialista na matéria, Dr. LOWRYE NELSON, que se encontra neste país para visitar as comunidades beneficiadas pelo programa e estudar a possibilidade de estender êsse benefício a outras localidades brasileiras.

No setor de Turismo, o Ponto IV forneceu especialistas que, trabalhando com técnicos brasileiros do Conselho Nacional de Turismo da Confederação Nacional do Comércio, elaboraram um relatório que analisa as perspectivas 
de turismo no Brasil. Na consecução de outro programa específico, o de comunicação áudio-visual, o Ponto IV manteve colaboração com a Campanha Nacional de Educação Rural. Trata-se de estabelecer um Centro de Treinamento para Técnicos em produções áudio visuais e de criar um CentroPiloto regional para treinamento de professôres e o preparo de pessoal de campo necessário à execução dos programas.

Alguns seminários sôbre comunicações áudio-visuais já se têm realizado com a participação de inúmeros técnicos interessados. Entre êstes seminários, inclui-se o Terceiro Estágio Latino-americano de Comunicações Áudiovisuais realizado na Fazenda Rosário, em Minas Gerais e de cuja organização participaram o I.N.E.P. e o Ponto IV, que forneceu todo o equipamento de instrução e os materiais de consumo necessários.

No campo da Energia Nuclear, está presente o. Ponto IV, ao proporcionar treinamento especializado para o uso, manutenção e operação de reatores de pesquisa. Mencionaremos ainda o treinamento em aerofotogrametria, o qual, por acôrdo firmado em 1953, com o Conselho Nacional de Geografia, especializa técnicos brasileiros nos diferentes aspectos dessa matéria. Mais de 60 técnicos já receberam tal treinamento e colaboram, hoje, no levantamento topográfico e aéreo do território nacional.

Pela análise dos variados programas que compõem a cooperação técnica do Ponto IV no Brasil, o treinamento especializado de técnicos brasileiros, tanto no Brasil como nos Estados Unidos, representa parte importante do processo pelo qual se procura acelerar o nosso desenvolvimento. Esses técnicos, pelas òbservações que fazem e pelo intercâmbio de idéias e sistemas, decorrentes de seu estágio no exterior, trazem uma contribuição necessária ao aperfeiçoamento de nossos próprios métodos, sendo que mais de dois mil brasileiros já receberam treinamento nos Estados Unidos em todos os setores que acabamos de analisar.

\section{PERSPECTIVAS DO PONTO IV}

Um relance retrospectivo leva a concluir que o regime de cooperação bilateral brasileiro-americano tem evoluido entre nós como o enunciado da lei de Spencer, isto é, vem passando, progressiva e construtivamente, do homogêneo confuso, ou melhor, assistemático, para o heterogêneo coordenado, ou mais precisamente, sistemático. De 1940 a 1950 sucederam se projetos e acôrdos individuais não entrosados num programa geral; a partir do acồrdo de 1950, quer dizer, a começar da vigência do Ponto IV, a cooperação bilateral se desenvolve em sistema. Com efeito, após o acôrdo básico, estabeleceu-se, ao lado da coordenação norte-americana, a coordenação brasileira, que teve na pessoa do eminente Senador Apolônio SALEs seu primeiro dirigente. Coincidência interessante: mesmo nessa fase, o escritório da coordenação já estava topogràficamente situado no D.A.S.P. Como os trabalhos parlamentares absorvessem as atividades de meu ilustre antecessor, êste me distinguiu com a indicação de meu nome, para substitui_lo, ao Exmo. Sr. Presidente Juscelino Kubitschek. Órgão de estado maior 
administrativo, o D.A.S.P. passaria a oferecer apoio técnico no exame dos projetos administrativos do Ponto IV. Consolidava-se, por tal meio. a coordenação dos programas de assistência técnica, no lado brasileiro. E nova coincidência vem fortalecer no conjunto o funcionamento do sistema. Refiro-me à designação do Ministro Howard R. CotTam para chetiar a coordenação no lado americano. S. Ex inaugurou, com a atual coordenação brasileira, a prática efetiva da cooperação bilateral, tornando-se possivel, assim, pôr em funcionamento, de modo harmônico e sistemático, as duas coordenações de programas.

Instituiram-se, então, as reuniões semanais para exame e discussão dos pedidos de assistência técnica; fixaram-se prioridades para aceitação bilateral e implantação dos programas; dinamizou-se todo o sistema. Em conseqüência, multiplicaram-se os projetos nos diversos setores da administração geral e especifica; intensificou se o intercâmbio de técnicos e bolsistas e personalidades, entre o Brasil e os Estados Unidos. Só em 1958 verifica-se o ativo de 127 projetos administrativos, de 293 bolsistas brasileiros nos Estados Unidos e de 143 técnicos americanos para o Brasil, tudo isso importando em investimento superior a oito milhões de dólares, incluido o programa de erradicação da malária. Essa rápida enumeração mostra como, exatamente no quadro cronológico de realizações do atual govêrno brasileiro, o Ponto IV atingiu posição de relêvo. E na consecução dêsses resultados, é justiça assinalar o apoio sempre presente que a todos os assuntos da cooperação bilateral dispensou S. Ex ${ }^{n}$, o Embaixador Ellis BRIGgs, entusiasta amigo do Brasil, que o conhece como se brasileiro fôra. Foi em companhia de Sua Excelência que tive a honra de assistir, em 1957, à conclusão de um empreendimento do Ponto IV, a saber, a inauguração do abastecimento d'água de Feira de Santana, no Estado da Bahia.

É fácil ver que, diante dos resultados concretos da cooperação bilateral, muito se fortaleceu a fraternidade brasileiro-americana. É que o considerável contingente de brasileiros que vão aos Estados Unidos, bem como o de técnicos americanos que vêm ao Brasil entrelaçam as duas pátrias. De minha parte, confesso que ao visitar os Estados Unidos, plantei na alma impressões indeléveis de um país maravilhoso, onde se fixou o que de mais grandioso produziu o homem; de uma sociedade estupendamente organizada e de um povo de alma aberta a seus hóspedes. Guardo na memória, os debates com autoridades americanas, por exemplo, com o Sr. William Johnsson, sôbre os projetos de recursos minerais; com $\mathrm{Mr}$. Arthur Syram, sôbre os de transporte; com Mr. EDWARD BERMAN, sôbre os de Educação; com Hiram S. Phillips e Mackee Rosen, sôbre a administração pública; revivo todos os encontros com dirigentes administrativos do Bureau of Budget, do «Civil Service Commission»; do «General Services Administration», enfim, com dezenas de outras personalidades americanas com quem mantive contatos. Como nos enterneceu ver que todos se mostravam grandemente interessados no programa governamental brasileiro, em particular, no empreendimento da construção de Brasilia e da transferência, para aí, da administração federal. De modo geral, o contato com os Estados Unidos há de transfundir no visitante brasileiro, de início, alta dose de admiração pelo que a civilização norte-americana oferece de espetacular; em segundo lugar, amalgama essa admiração com o tônus de amizade e fraternidade pelo que 
de tão acolhedor lhe apresenta o homem americano. E bem consideradas tôdas as suas qualidades pessoais, não mais causará espanto a afirmação de JaCques Montani, segundo a qual o povo norte-americano é altamente espiritualizado.

Por tudo isso se pode concluir que o Ponto IV, no Brasil, não apenas chega, a esta altura, a sedimentar os resultados concretos acima apontados, mas ainda conduz a estreitar ainda mais a fraternidade brasileiro-americana.

Diante dêsses pressupostos atuais, ampliam-se as perspectivas da coope ração bilateral. Mais de cem projetos administrativos estão em curso através do Ponto IV, abrangendo os setores administrativos fundamentais. Êsse fato agora adquire maior importância se se considerar que tais programas se podem conjugar com as metas governamentais. Como estas, tendem ao objetivo comum de desenvolvimento social e econômico de nosso país. Como tal desiderato vem polarizando o Govêrno para uma ação global de mobilização de todos os fatôres de grandeza nacional, é oportuno almejar maior participação do Ponto IV como apoio aos programas administrativos de âmbito geral. Necessário se torna preparar caminho a esta nova fase de cooperação, dando-se organização técnica adequada ao escritório da coordenação brasileira. Providências nesse sentido estão sendo ultimadas com êxito, em articulação com o Ministério das Relações Exteriores, de acôrdo com a orientação dinâmica que o Itamarati vem imprimindo aos assuntos de amplitude internacional, dentro do quadro geral da política exterior do país.

Confiamos em que, preparado por nós o meio para novo e mais alto «standard» de cooperação, o lado americano do Ponto IV virá ao nosso encontro, com novos setores de cooperação, novos e mais substanciais investimentos. Na presente dimensão das relações internacionais, a fôrça dos povos está em sua solidariedade cultural reciproca. Para o Brasil, lançou EuClides DA CunHA, há mais de meio século, esta alternativa temerosa: «ou progredimos ou perecemos». É fora de dúvida que o Brasil está progre dindo, e muito. Mas o maior perigo hoje, quando se considera a interdependência internacional, a constituição de zonas de influência política e, particularmente, a divisão do mundo em dois hemisférios ideológicos - o da democracia e o da ditadura - o maior perigo - repitamos - é progredir ou estagnar sòzinho, na sociedade aberta que vivemos. Impõe-se, em contraposição, o progresso conjunto e sincrônico dós países e, no que nos toca particularmente, do continente americano. Neste preceito assentam, em última análise, os sistemas de cooperação multilateral e bilateral, e iniciativas da mais alta importância como a da Operação Pan-Americana. Como instri1mento de cooperação bilateral, o Ponto IV ai se inclui específicamente como traço de união entre o Brasil e os Estados Unidos, e suas atuais perspectivas, acima delineadas, devem convergir para êste horizonte histórico: o progresso do Brasil para que, irmanado ao progresso dos Estados Unidos, possa constituir nossos dois países em pólos inabaláveis da solidariedade continental. 